University of Wollongong

Research Online

Faculty of Engineering and Information

Faculty of Engineering and Information

Sciences - Papers: Part A

Sciences

$1-1-2014$

\title{
Climate change mitigation with integration of renewable energy resources in the electricity grid of new south wales, Australia
}

Md Abu Abdullah

University of Wollongong, maa267@uowmail.edu.au

Ashish Agalgaonkar

University of Wollongong, ashish@uow.edu.au

Kashem M. Muttaqi

University of Wollongong, kashem@uow.edu.au

Follow this and additional works at: https://ro.uow.edu.au/eispapers

Part of the Engineering Commons, and the Science and Technology Studies Commons

Research Online is the open access institutional repository for the University of Wollongong. For further information contact the UOW Library: research-pubs@uow.edu.au 


\title{
Climate change mitigation with integration of renewable energy resources in the electricity grid of new south wales, Australia
}

\begin{abstract}
The implementation of climate change mitigation strategies may significantly affect the current practices for electricity network operation. Increasing penetration of renewable energy generation technologies into electricity networks is one of the key mitigation strategies to achieve greenhouse gas emission reduction targets. Additional climate change mitigation strategies can also contribute to emission reduction thereby supplementing the renewable energy generation participation, which may be limited due to technical constraints of the network. In this paper, the penetration requirements for different renewable energy generation resources are assessed while concurrently examining other mitigation strategies to reduce overall emissions from electricity networks and meet requisite targets. The impacts of climate change mitigation strategies on the demand and generation mix are considered for facilitating the penetration of renewable generation. New climate change mitigation indices namely change in average demand, change in peak demand, generation flexibility and generation mix have been proposed to measure the level of emission reduction by incorporating different mitigation strategies. The marginal emissions associated with the individual generation technologies in the state of New South Wales (NSW) are modelled and the total emissions associated with the electricity grid of NSW are evaluated. 2013 Elsevier Ltd.
\end{abstract}

\section{Keywords}

renewable, integration, mitigation, change, wales, south, australia, grid, climate, electricity, resources, energy

\section{Disciplines}

Engineering | Science and Technology Studies

\section{Publication Details}

M. Abdullah, A. P. Agalgaonkar \& K. Muttaqi, "Climate change mitigation with integration of renewable energy resources in the electricity grid of new south wales, Australia," Renewable Energy, vol. 66, (June) pp. 305-313, 2014. 


\title{
Climate Change Mitigation with Integration of Renewable Energy Resources in the Electricity Grid of New South Wales, Australia
}

\author{
M. A. Abdullah, A. P. Agalgaonkar and K. M. Muttaqi \\ Endeavour Energy Power Quality and Reliability Centre (EEPQRC), School of Electrical, Computer and \\ Telecommunications Engineering, University of Wollongong, Wollongong, New South Wales, 2522, Australia. \\ (e-mails: maa267@uowmail.edu.au; ashish@uow.edu.au; kashem@uow.edu.au)
}

\begin{abstract}
The implementation of climate change mitigation strategies may significantly affect the current practices for electricity network operation. Increasing penetration of renewable energy generation technologies into electricity networks is one of the key mitigation strategies to achieve greenhouse gas emission reduction targets. Additional climate change mitigation strategies can also contribute to emission reduction thereby supplementing the renewable energy generation participation, which may be limited due to technical constraints of the network. In this paper, the penetration requirements for different renewable energy generation resources are assessed while concurrently examining other mitigation strategies to reduce overall emissions from electricity networks and meet requisite targets. The impacts of climate change mitigation strategies on the demand and generation mix are considered for facilitating the penetration of renewable generation. New climate change mitigation indices namely change in average demand, change in peak demand, generation flexibility and generation mix have been proposed to measure the level of emission reduction by incorporating different mitigation strategies. The marginal emissions associated with the individual generation technologies in the state of New South Wales (NSW) are modelled and the total emissions associated with the electricity grid of NSW are evaluated.
\end{abstract}

Keywords: Climate change mitigation; emission reduction; performance indices; renewable energy penetration.

\section{Introduction}

Fossil fuel based conventional power plants produce a large amount of greenhouse gas (GHG) emissions. To mitigate climate change disorder in electricity generation, deployment of mitigation technologies for reduction of GHG emissions is essential [1]-[4]. Climate change mitigation techniques such as use of renewable energy resources in power generation including change in fuel mix, energy efficient appliances, demand side management strategies, and smart appliances can be applied to reduce emissions from electricity infrastructure [1-2]. Mitigation strategies are required to be developed for introducing such a transition in the well-established power sector. Assessment and quantification of the emission reduction ability for an electricity system with varying penetration of renewable power generation are required to achieve the national and international emission targets [5].

Several economic theories, such as integration of renewable energy resources in the grid, have been reported in the literature to assess the impact of climate change mitigation strategies on the electricity infrastructure. In [3], the author has presented a comparative analysis of the costs associated with and without implementation of GHG emission reduction policies for the Australian electricity sector. The authors in [4] have presented the simulated results detailing impacts of climate change mitigation technologies on power system. In [4], electricity generation cost, energy price, emission rate and transmission congestion are used as the performance indicators for the different technologies. However, cost may not be a suitable indicator of the mitigation ability of an electricity network, especially in the presence of different government incentive schemes and consumer willingness to pay for enacting climate change mitigation.

A composite GHG emission reduction model has been developed in [6] considering emission savings from renewable energy resources, and transmission and distribution efficiency improvements. The integration of renewable generation systems and adoption of carbon price are considered as the climate change mitigation strategies; and marginal emission is used as the performance indicator. In [7], marginal emission of the conventional generation system is used to compute the emission offset from the installation of wind generation systems. Variation in annual emissions is shown as the mitigation indicator for different installed capacities of wind generation systems. In [8], linear programming model is developed to assess the optimal generation mix for the electricity network with high penetration of wind power generation. The different options of generation 
mix are evaluated with the aid of different ramp rates of the associated generation technologies, transmission interconnection flexibility and energy storage flexibility in the network. In [9], the emission rate of coal and gas power plants is modelled and impact of system flexibility constraints on the penetration of intermittent generation systems in the electricity network is assessed. The authors of [10] have assessed the impact of system flexibility factor on the penetration of solar photovoltaic (PV) generation systems. It considers surplus energy, capacity factor and energy cost as the mitigation indices of the system. In [11], the effects of climate change mitigation technologies on the penetration of the solar PV system are investigated. System flexibility, energy storage systems and peak load shaving schemes are considered as the mitigation techniques, and the unit cost of energy is used as an indicator for the mitigating of the electricity system.

The emissions from different generation technologies are modelled in [12] considering the variations in the loading levels of the generating units. Emission factor, which is the average GHG emission associated with the per unit energy generation from the plant, is used to estimate the emission from the generation plant corresponding to the net energy generation [13-15]. In [14], emission factor of the input fuel is used to calculate the $\mathrm{CO}_{2}$ emission from combined heat and power plants. In [15], emission factor is used to evaluate the emissions of the pollutant gases from the distributed cogeneration power plants. However, the GHG emissions from generation plants depend on the output of the generators and emission factor of the plant cannot incorporate the fluctuations in GHG emissions due to the varying output of the generators [16-17]. The dependency of $\mathrm{CO}_{2}$ emissions of the coal fired power plant on the efficiency of the plant is considered in [16] in order to estimate the $\mathrm{CO}_{2}$ emissions. In [17], an empirical function of generated power from the generators is used to estimate the emissions from the thermal power generation plants. A number of unit commitment algorithms can be found in the literature [18-22] to determine economic dispatch of generating units for emission reduction. In the emission constrained unit commitment presented in [18-22], empirical models of emissions have been formulated to estimate the total emission from electricity generation. In [21-24], constant emission factor and nonlinear functions of power output have been used to model the emission from generation plants.

The New South Wales (NSW) state government in Australia has set targets to contain emissions to the 2000 levels by 2025 and reduce emissions by $60 \%$ by 2050 [25]. In order to achieve the emission reduction target, mitigation strategies are set for different sectors such as energy generation, agriculture, transportation and industrial production. In order to reduce emission from electricity generation, renewable energy generation targets (RET) are set and additional schemes such as carbon tax, incentives on renewable generation systems, energy storage integration, introducing electric vehicles, use of energy efficient appliances are planned to be introduced [25]. These mitigation schemes have impacts on the NSW electricity network such as change in load demand, generation mix, generation flexibility, etc. Depending upon the changes in NSW electricity network, the emissions from electricity generation would be altered, and required renewable generation penetration to achieve NSW emission reduction target from electricity generation would be different. Hence, it is necessary to assess the impacts of climate change mitigation strategies on NSW electricity network and possible emission reduction from electricity generation systems with the increased penetration of renewable generation systems need to be investigated [26].

In this paper, the impacts of climate change mitigation strategies are assessed to achieve emission reduction targets with the increasing penetration of renewable energy generation in the electricity network. The mitigation indices based on the impacts of the mitigation strategies on the demand and generation mix are developed. Change in average demand, variation in peak and off-peak demand, generation flexibility and generation mix index are considered to evaluate the impact of climate change mitigation strategies on facilitating the renewable generation growth in the electricity network. The marginal emission of the individual generation plant is modelled using thermodynamic model of the plant. The emission model for the energy supplied in the grid from different generation plants is developed based on the fuel mix of the grid. The penetration levels of different renewable energy resources have been evaluated to achieve the set emission reduction target for NSW electricity grid.

\section{Impacts of Climate Change Mitigation Strategies on Electricity Networks}

The extensive usage of renewable energy resources within technical constraints can be one of the attractive options to reduce GHG emissions in the electricity networks. The penetration level of renewable energy generation and the emission offset from conventional i.e. non-renewable generation systems can be considered as indicators to examine climate change mitigation performance of the electricity infrastructure. It is noted that the relationship between emission reduction and penetration of the renewable energy generation is nonlinear [27]. For higher penetration, the emission reduction per unit installed capacity becomes lower due to the curtailment of excess energy. The penetration of the renewable resources can be expressed in terms of their installed capacity with respect to the peak load demand of the network. The emission offset due to the integration of renewable generation systems can be expressed by the fraction of emission reduced from the base case emission. 
The conventional strategies and practices in electricity networks may not be significantly beneficial for achieving the emission curtailment target [1]. The uncertainties associated with the power availability from renewable resources, such as solar PV and wind generation, could be one of the major barriers for accommodating renewable generation systems in the electricity infrastructure. In order to accommodate high penetration of renewable energy resources in the electricity infrastructure, novel climate change mitigation strategies need to be developed. The implementation of energy efficient equipment, electric vehicles, demand side management schemes and fuel efficient generation plants can be considered as some of efficient strategies of climate change mitigation. The mitigation strategies can affect the load demand of the network and the operation of conventional, non-renewable generating resources. The effects of various mitigation strategies on the relationship between emission reduction and penetration level of renewable generation are required to be quantified for assessing the effectiveness of their applicability.

\subsection{Impacts on electricity demand}

Implementation of the energy efficient appliances, electric vehicles and demand side management can influence the average daily load demand in the network $[28,29]$. These mitigation strategies can change the daily energy consumption and hence the average daily load demand as shown in Fig. 1. The changes in daily load pattern of the network due to 10\% increase and 10\% decrease in average daily load are shown in Fig. 1. The average load demand shift can be expressed using (1).

$$
\Delta \mu_{L}=\frac{\mu_{L}^{\prime}-\mu_{L, \text { Base }}}{\mu_{L, \text { Base }}}
$$

Where, $\Delta \mu_{L}$ is the average demand shift. $\mu_{L}^{\prime}$ and $\mu_{L, B a s e}$ are the average daily demand with and without implementation of mitigation strategies, respectively. Negative value of $\Delta \mu_{L}$ means that the average daily load demand of the network has been reduced. On the other hand, positive value of $\Delta \mu_{L}$ indicates that the average daily load of the network has been increased. If the daily load pattern of the system remains unchanged and only the average demand is shifted, the estimated shifted demand $L^{\prime}(h)$ at time $h$ of the day can be computed using (2).

$$
L^{\prime}(h)=L(h) \times\left(1+\Delta \mu_{L}\right)
$$

Where, $L(h)$ is the estimated demand of the system at time $h$ of the day for the base case.

Application of the demand side management schemes such as time varying rate, smart appliances, schedulable load and use of energy storage systems can affect the peak and off-peak load demand of the network [11]. Due to the application of such mitigation strategies, the daily average load demand of the system remains unchanged while the load is shifted from peak hours to the off-peak hours changing the shape of the daily load pattern as shown in Fig. 2. There may be more than one way to shift the load pattern based on the strategies applied for load shifting. In this paper, it is assumed that the shifted load demand from the peak hours is evenly distributed among the off-peak hours and the quantity of the shifted load at each hour is proportional to the demand at that hour. The change in the variation of peak demand and off-peak demand of the system can be presented using (3)

$$
\Delta L_{\mathrm{var}}=\frac{L_{\text {max }}^{\prime}-L_{\text {min }}^{\prime}}{L_{\max }-L_{\min }}
$$

Where, $\Delta L_{v a r}$ is the change in the variation between peak demand and off-peak demand. $L_{\max }$ and $L_{\min }$ are the maximum and minimum load demand of the system in a day without mitigation strategies, respectively. $L_{\max }^{\prime}$ and $L^{\prime}{ }_{\text {min }}$ are the maximum and minimum load demand of the system in a day with the application of mitigation strategies, respectively. The value of $\Delta L_{\text {var }}$ less than 1 indicates that difference between peak demand and offpeak demand of the system is decreased with the application of demand side management strategies, and vice versa. In addition, negative value of $\Delta L_{v a r}$ indicates that the peak load is shifted from peak demand time to the off-peak demand time of the day. The estimated demand $L^{\prime \prime}(h)$ at time $h$ of the day can be computed using (4).

$$
L^{\prime \prime}(h)=\left(L(h)-\mu_{L}\right) \times \Delta L_{\mathrm{var}}+\mu_{L}
$$

Where, $L(h)$ is the estimated demand of the system at time $h$ of the day for the base case. $\mu_{L}$ is the daily average load of the system. 


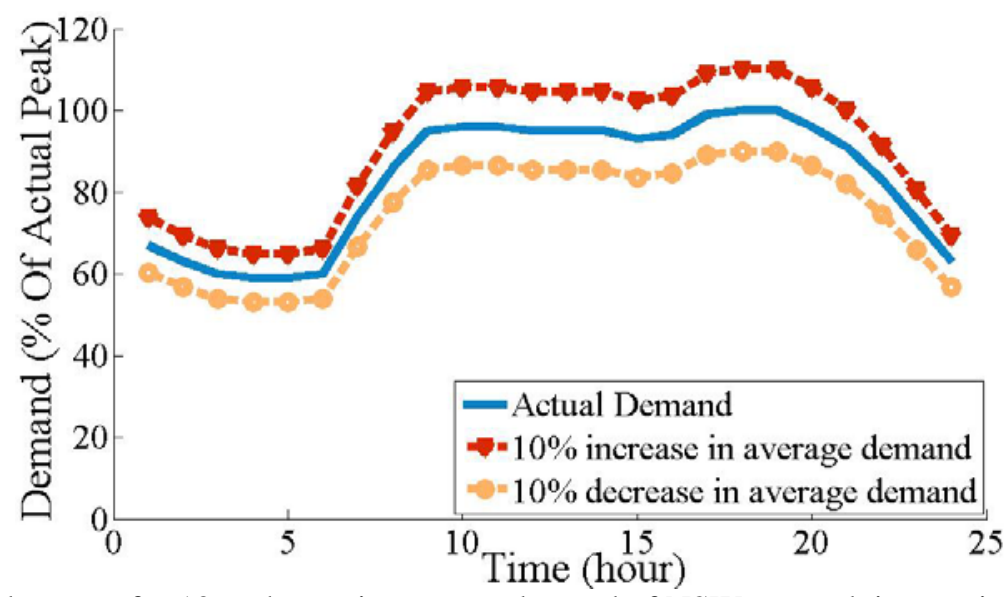

Fig. 1. Daily load pattern for $10 \%$ change in average demand of NSW network in a typical day of January.

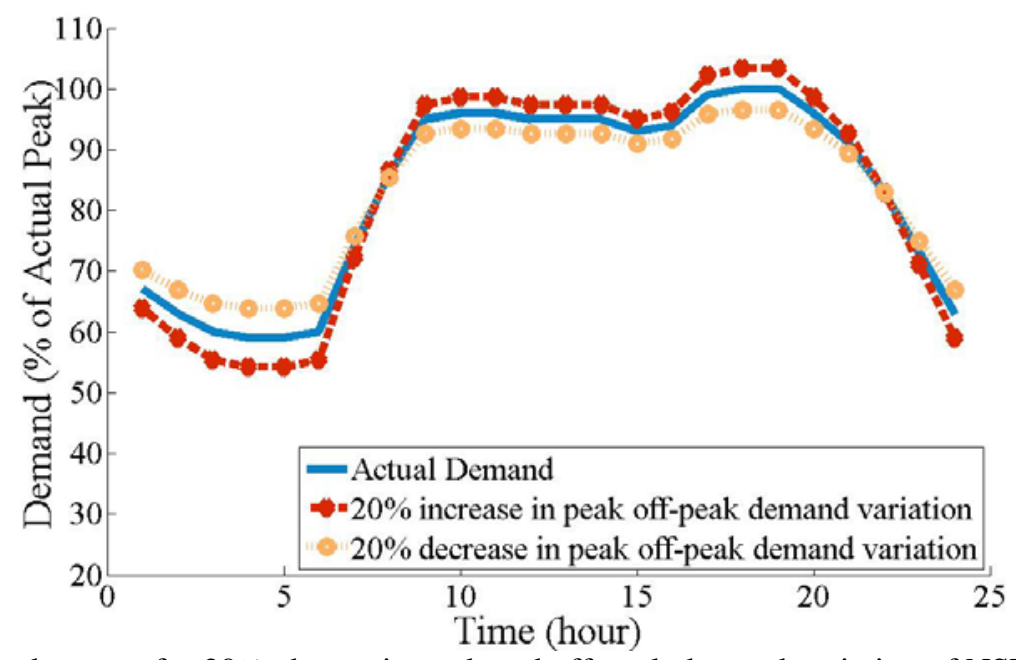

Fig. 2. Daily load pattern for $20 \%$ change in peak and off-peak demand variation of NSW network in a typical day of January.

\subsection{Impacts on electricity generation systems}

Improved accuracy of the load demand and generation forecasting can reduce the minimum generation level of the conventional, i.e. non-renewable generating resources $[10,11]$. This will increase the generation flexibility of the system and aid in accommodating higher penetration of the intermittent renewable energy generation systems. The generation flexibility of the system can be defined as given in (5).

$f_{\text {Flex }}=\frac{L_{\max }-G_{\min }}{L_{\max }}$

Where, $f_{\text {Flex }}$ is the generation flexibility of the conventional, i.e. non-renewable generation system. $L_{\max }$ is the maximum demand of the system, and $G_{\text {min }}$ is the minimum total generation level that can be reduced by all the conventional generation plants in the system. $f_{\text {Flex }}$ can be between 0 to 1 . Higher value of the flexibility of the system with conventional resources indicates that the system can accommodate higher penetration of intermittent generation systems by reducing the minimum generation level of the conventional resources.

With the increase in generation flexibility of the system, the minimum generation level of conventional resources decreases. The energy difference between minimum generation level of the conventional resources and the load demand can be supplied by the intermittent generation systems. The contribution of the renewable energy can be increased in meeting the energy demand thereby reducing the minimum generation level for which the conventional resources need to be operated. The minimum generation level of the conventional generating resources can be computed using (6). 


$$
G_{\min }=L_{\max } \times\left(1-f_{\text {FLex }}\right)
$$

Reducing the share of generating stations with higher emission rate and increasing the share of generating stations with lower emission rate in the generation system can reduce the overall emissions from the generation system. Changing the shares of generation mixes will change the operational emission of the grid energy mix. Change in generation mix of the system can be presented in (7).

$f_{\text {Fuel }}=\frac{\sum_{i} P_{\text {Fuel }, i}}{\sum_{j} P_{\text {Fuel }, j}}$

Where, $f_{\text {Fuel }}$ is the index for the generation mix of the system. $P_{\text {Fuel, } i}$ is the normalised share of fuel, that is, changed in the fuel mix of the conventional generating resources. Higher value of $f_{\text {Fuel }}$ indicates the increased share of generation plants with fuel group $i$ (e.g. natural gas and bio-fuel) and reduced share of generation plants with fuel group $j$ (e.g. Coal).

The fuels used in the conventional generating systems can be divided into three groups namely increased share, reduced share and unchanged share. The sum of the normalised share of all the fuel groups is equal to one as given in (8).

$$
\sum_{i} P_{\text {Fuel }, i}+\sum_{j} P_{\text {Fuel }, j}+\sum_{k} P_{\text {Fuel }, k}=1
$$

Where, $i$ and $j$ are the fuel groups that needs to be shifted and $k$ is the fuel group which remains unchanged. Hence, the change in share of one group of fuel can be computed from the information of the share of the other fuel group and generation mix index as given by (9) and (10), respectively.

$$
\begin{aligned}
\sum_{j} P_{\text {Fuel }, j} & =\frac{1-\sum_{k} P_{\text {Fuel }, k}}{1+f_{\text {Fuel }}} \\
\sum_{i} P_{\text {Fuel }, i} & =\frac{f_{\text {Fuel }} \times\left(1-\sum_{k} P_{\text {Fuel }, k}\right)}{1+f_{\text {Fuel }}}
\end{aligned}
$$

For example, let us assume that fuel group $i$ represents natural gas fired power plants and fuel group $j$ represents coal fired power plants. The normalised share of the coal and natural gas fired power plants in the total generation capacity is assumed to be $60 \%$ and $30 \%$, respectively. Hence, the generation mix index has a value of 0.5 . If some of the coal fired power plants are replaced by natural gas fired power plants as a climate change mitigation strategy and the generation mix index is set to 0.6 , the normalised share of coal and natural gas fired power plant in the total generation capacity can be found $56.25 \%$ and $33.75 \%$ using (9) and (10), respectively.

\section{Modelling of the Aggregated Marginal Emissions of the Electricity Grid}

The assessment of the impact of climate change mitigation strategies on the emission mitigation performances requires the modelling of the emissions from conventional generating resources. The emission rates for the different generating plants are different. In addition, emission rate of the individual plant may also be different depending upon their loading levels. The load demand in an electricity network is time varying and hence, the emissions associated with unit energy generation will also be time dependent.

Emission factor is an average quantity of the marginal emission of the corresponding generation plants and is readily available from the generator manufacturers. In order to model each type of pollutant gas emission as a nonlinear function of output power, the operational data of that pollutant gas emission from the generation plants are required. In this paper, the marginal emission from different generation plants has been modelled from the thermal properties of the corresponding fuel and generation plant. Also, equivalent global warming potential of each pollutant gas emission has been considered in estimating the total emission reduction from climate change mitigation strategies. 
Coal, oil and natural gas are some of the commonly used fossil-fuels for running the conventional power plants worldwide. Beside these fossil fuel based power plants, some renewable energy based power plants have a significant share in the grid mix. Since, hydro, wind and solar PV based power plants release minimal emissions in their operational phase, the operational emissions of these power plants can be considered to be equal to zero. For fossil fuel based power plants, discharge of different gasses from unit energy generation can be expressed using (11) and (12).

$$
\begin{aligned}
& M E_{G, i, C a l}=f_{\text {sif }, m, f u e l} \times \frac{1-E_{\text {control }, G}}{f_{\text {sim, } m, G} \times U H V_{f u e l}} \\
& M E_{G, i, E l e c}\left(f L_{i}\right)=\frac{3.6 \times 10^{3} \times M E_{G, i, C a l}}{\eta_{i}\left(f L_{i}\right)}
\end{aligned}
$$

Where, $f L_{i}$ is the ratio of operating load to the rated load of the $i^{\text {th }}$ power plant. $G$ is the type of gas discharge and $i$ indicates the power plant type. $M E_{G, i, C a l}$ is the rate of $G$ gas discharge $(\mathrm{kg} / \mathrm{MJ})$ from the $i^{\text {th }}$ power plant and $m$ is the substances in the polluting gas $G$ contained in the fuel. $f_{s i m, m, G}$ and $f_{s i f, m, f}$ are the fractional mass content of substance $\mathrm{m}$ in the gas $G$ and fractional mass content of substance $\mathrm{m}$ in the fuel $f$, respectively. $E_{\text {control, } G}$ is the rate of $G$ gas discharge control in the power plant during the operation cycle and $U H V_{\text {fuel }}$ is the higher heating value $(\mathrm{MJ} / \mathrm{kg})$ of the fossil fuel used in the power plant. $M E_{G, i, E l e c}\left(f_{L, i}\right)$ is the rate of $G$ gas discharge $(\mathrm{kg} / \mathrm{MWh})$ from $i^{\text {th }}$ power plant to produce 1 MWh electricity while running at $f L_{i}$ fraction of rated load. $\eta_{i}\left(f L_{i}\right)$ is the efficiency of $i^{\text {th }}$ power plant while generating power at $f L_{i}$ of rated condition. $\mathrm{CO}_{\mathrm{x}}, \mathrm{NO}_{\mathrm{x}}, \mathrm{N}_{2} \mathrm{O}$ and $\mathrm{SO}_{\mathrm{x}}$ are some of the common emitted gases from the fossil fuel based power plants. The fractional mass content of substance from fuel in some of the common pollutant gases emitted from power plants are given in Table 1. Since Oxygen is the common element in the pollutant gases, the fractional mass content of Oxygen can be calculated by subtracting the fractional mass content of the element $\mathrm{m}$ in gas $\mathrm{X}$ from 1 , i.e. $f_{\text {sim }, O 2, X}=\left(1-f_{\text {sim }, m, X}\right)$.

\section{TABLE 1}

Fractional mass content of element, $\mathrm{m}$ in gas $G$

\begin{tabular}{|l|l|l|}
\hline Gas, $\boldsymbol{G}$ & Element, $\boldsymbol{m}$ & Fraction, $\boldsymbol{f}_{\text {sim, }, \boldsymbol{G}}$ \\
\hline $\mathrm{CO}_{2}$ & Carbon & 0.27 \\
\hline $\mathrm{CO}$ & Carbon & 0.43 \\
\hline $\mathrm{SO}_{2}$ & Sulphur & 0.5 \\
\hline $\mathrm{N}_{2} \mathrm{O}$ & Nitrogen & 0.636 \\
\hline $\mathrm{NO}$ & Nitrogen & 0.467 \\
\hline $\mathrm{NO}_{2}$ & Nitrogen & 0.304 \\
\hline
\end{tabular}

The energy conversion efficiency of generating units and hence power plants varies for various loading levels. The efficiency of the power plant at different loading conditions can be modelled using the rated efficiency and the efficiency de-rating factor as shown in (13).

$\eta_{i}\left(f L_{i}\right)=\eta_{i, \text { Rated }} \times f P_{i}\left(f L_{i}\right)$

Where, $\eta_{\mathrm{i}, \text { rated }}$ is the rated efficiency of the $i^{\text {th }}$ power plant. $f P_{i}\left(f_{L, i}\right)$ is the efficiency de-rating factor of the $i^{\text {th }}$ power plant for operating at $f_{L, i}$ fraction of rated loading condition. Assuming the efficiency de-rating factor of the generating units follows a linear relationship with the fraction of rated load, it can be expressed as shown in (14),

$$
f P_{i}\left(f L_{i}\right)=\alpha+\beta \times f L_{i}
$$

Where, $\alpha$ and $\beta$ are two coefficients, which depend on the plant type, size, operating temperature, etc. Moreover, energy supplied through the utility system is composed of energy generated by different power plants using different fuels. The generating plants are dispatched economically to generate power at different levels 
depending upon the net load demand of the electricity network. Some power plants can be classified as base load power stations, some other can be classified as intermediate power plants and others can be classified as peak power plants based on the characteristics of the power plants. Fig. 3 shows an example of a load duration curve of a power system composed as the shares of different fuel based generators in meeting the demand of the system. From the information about the type of fuels, number of power plants, plant capacity and unit operation schedule of the system, rate of discharge of the polluting gases for the base, intermediate and peak demand can be formulated as below.

$$
\begin{aligned}
& T E_{G, \text { Base }}=\left\{\sum_{i} M E_{G, i, \text { Elec }}(1) \times w_{i}\right\} \times g_{B} \\
& T E_{G, \text { Int }}\left(f_{D}\right)=\left\{\begin{array}{lc}
{\left[\sum_{i} M E_{G, i, E l e c}\left(\frac{\left(f_{D}-g_{B}\right) \times w_{i}}{\left(g_{I}-g_{B}\right) \times x_{i}}\right) \times w_{i}\right] \times\left(f_{D}-g_{B}\right)} & \text { for, } g_{B} \leq f_{D} \leq g_{I} \\
{\left[\sum_{i} M E_{G, i, E l e c}(1) \times w_{i}\right] \times\left(g_{I}-g_{B}\right)} & \text { for, } g_{I}<f_{D}
\end{array}\right. \\
& T E_{G, \text { Peak }}\left(f_{D}\right)=\left\{\begin{array}{lc}
0 \\
{\left[\begin{array}{l}
\sum_{i} M E_{G, i, E l e c}\left(\frac{\left(f_{D}-g_{I}\right) \times w_{i}}{\left(g_{P}-g_{I}\right) \times x_{i}}\right) \times w_{i}
\end{array}\right] \times\left(f_{D}-g_{I}\right)} & \text { for, } f_{D} \leq g_{I}
\end{array}\right.
\end{aligned}
$$

Where, $f_{D}$ is the demand level of the grid. $T E_{G, B a s e}, T E_{G, I n t}$ and $T E_{G, P e a k}$ are the aggregated emission of $G$ gas associated with base, intermediate and peak demand, respectively. $M E_{G, i, E l e c}, w_{i}$ and $x_{i}$ are the rate of $G$ gas discharge, normalised dispatched power and fraction of installed generation capacity supplied by the $i^{\text {th }}$ type power plant, respectively. $g_{B}, g_{I}$ and $g_{P}$ are the maximum demand level for base, intermediate and peak demand for generation plant classification, respectively. The derivation of equations (15)-(17) is presented in Appendix A with example of equation (16). The aggregated rate of GHG discharge of the grid mix, $T E_{G, G r i d}\left(f_{D}\right)$ can be computed using (18).

$$
T E_{G, \text { Grid }}\left(f_{D}\right)=T E_{G, \text { Base }}+T E_{G, I n t}\left(f_{D}\right)+T E_{G, \text { Peak }}\left(f_{D}\right)
$$

The discharge rate of the grid mix for different gases during different demand level can be expressed in terms of global warming potential. The marginal $\mathrm{CO}_{2}$ equivalent emission of the grid mix for the normalised demand level $f_{D}$ can be computed using (19).

$T E_{\text {Grid }}\left(f_{D}\right)=\sum_{G} \alpha_{G} \times T E_{G, \text { Grid }}\left(f_{D}\right)$

Where, $\alpha_{G}$ is the equivalent global warming potential of $G$ type gas in $\mathrm{kg} \mathrm{CO}_{2}$-eq $/ \mathrm{kg}$ and $T E_{G r i d}\left(f_{D}\right)$ is the total equivalent global warming potential emission of the grid mix in $\mathrm{kg} \mathrm{CO}_{2}$-eq/MWh. The chronological emission of the grid mix can be computed using the unit commitment and the information about the marginal emission rates associated with each generation plant. Unit commitment has been used as a tool to estimate the output of each power plant during each dispatch interval. From the output level of each power plant during each dispatch interval, the marginal and total emission from that power plant is estimated using the presented emission model for that dispatch interval. Mixed integer linear programming algorithm is used to solve the unit commitment in this study. 


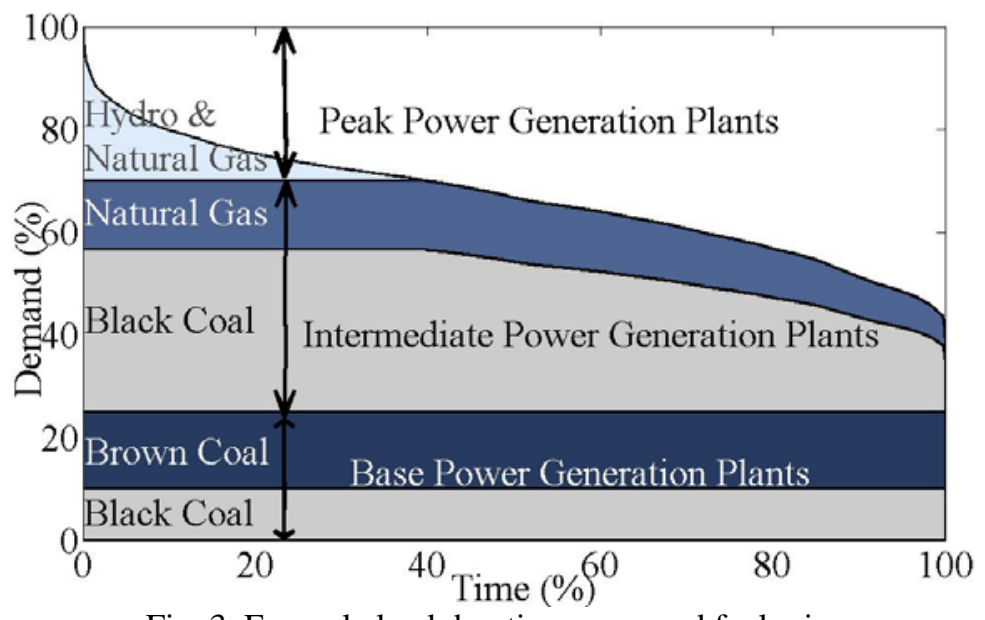

Fig. 3. Example load duration curve and fuel mix.

\section{Climate Change Mitigation in NSW Electricity Grid}

The proposed emission assessment methodology for various climate change mitigation strategies is assessed for the electricity network in New South Wales (NSW), Australia. The impacts of climate change mitigation strategies on the electricity network in achieving the mitigation target are assessed. Based on the National Transmission Network Development Plan 2011 (NTNDP) prepared by Australian electricity market operator [30], the total planning period of 10 years is considered with an overall load growth of $1 \%$ every year. Hourly average load demand and generation are used in the proposed study. The existing operational strategy is considered as the base case scenario. The share of existing installed capacity for the generating resources in the state of NSW [30] is shown in Fig. 4 using a pie chart. It can be noted that the natural gas to coal fuel ratio in NSW electricity generation system is 0.1667 in the current time. In this analysis, hydroelectric generation system is considered as the conventional generating resource with zero operational emission. It is assumed that the base case generation mix remains the same even with the prospective load growth. The higher heating value, particle contents of the coal and natural gas used in the Australian power plants are given in Table 3 [31, 32].

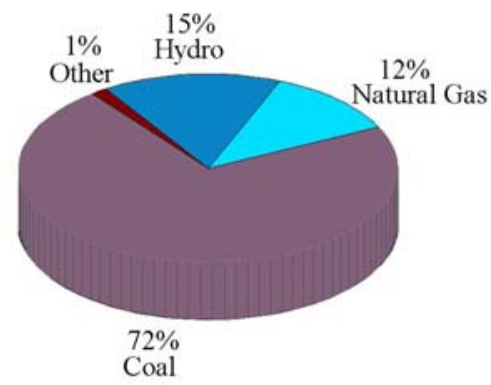

Fig. 4. Share of fuels in the grid mix of NSW, Australia

TABLE 2

Thermal property and composition of fuels used in NSW electricity generation plants

\begin{tabular}{|l|c|l|l|l|}
\hline $\begin{array}{c}\text { Fuel } \\
\text { Type }\end{array}$ & $\begin{array}{l}\text { Higher } \\
\text { Heating Value } \\
\text { (MJ/kg) }\end{array}$ & $\begin{array}{l}\text { Carbon } \\
\text { Content } \\
\text { (\%) }\end{array}$ & $\begin{array}{l}\text { Nitrogen } \\
\text { Content (\%) }\end{array}$ & $\begin{array}{l}\text { Sulphur } \\
\text { Content } \\
\text { (\%) }\end{array}$ \\
\hline Coal & $22.9-26.27$ & $57.1-64.5$ & $1.15-1.5$ & $0.34-0.55$ \\
\hline $\begin{array}{l}\text { Natural } \\
\text { Gas }\end{array}$ & 51.39 & 68.5 & 0 & 0.025 \\
\hline
\end{tabular}

Solar PV and wind energy conversion system (WECS) are considered as the renewable generation systems in the analysis. Three hypothetical scenarios are considered for maximising the renewable energy generation for 
climate change mitigation. In scenario 1, WECS is considered as the only available renewable generation technology while in scenario 2, solar PV generating system is the only renewable generation system. In scenario 3, hybrid combination of solar PV and WECS with equal capacities is considered as renewable generation system. In order to operate the network within technical constraints, it is assumed that excessive renewable generation can be curtailed using the curtailment strategy [33]. The impacts of different mitigation strategies on the penetration level of renewable resources are simulated using MATLAB and emission reduction capability corresponding to the penetration level is estimated for the state of NSW, Australia.

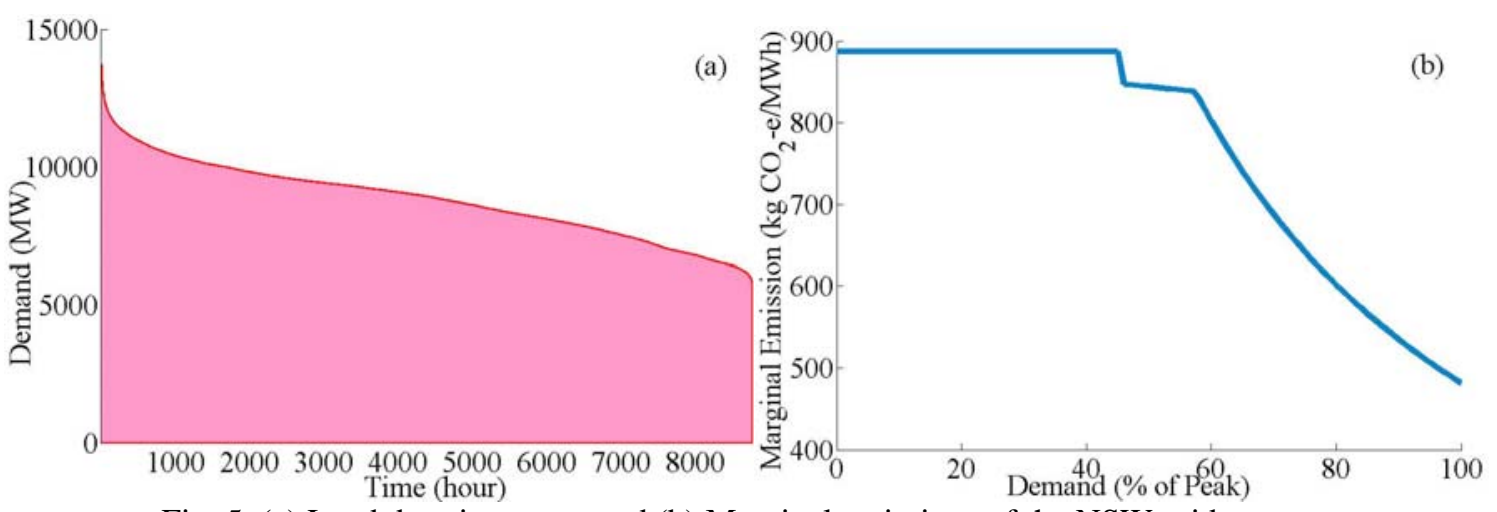

Fig. 5. (a) Load duration curve and (b) Marginal emissions of the NSW grid energy.

The load duration curve of NSW electricity network is shown in Fig 5(a). The marginal emissions associated with the electrical energy disseminated in the NSW grid are evaluated using the proposed marginal emission computation method and depicted in Fig. 5(b). The coal power plants are supplying the base load. The intermediate demand is served by the mix of coal and natural gas power plants and the peak demand is served by the hydro and natural gas power plants. Since the share of the gas turbine power plants increases with the increase in demand and most of the power plants are operated near their rated capacities with maximum efficiencies, the marginal emissions decrease with the increase in intermediate load demand. The GHG emission associated with the peak demand reduced significantly since hydro power plants are operated with zero emission during peak demand periods.

\section{1. $\quad$ Average Demand Shifting}

The impact of variation in average demand shift on the emission reduction and renewable generation system penetration for the three scenarios discussed above is shown in Fig. 6. Each scenario is simulated with $-10 \%, 0 \%$ and $10 \%$ increase in the average load of the NSW network. It is found that higher emission reduction is achievable with lower penetration of the renewable energy generation by reducing the average demand of the network. Moreover, it is noted that the marginal emission reduction with the inclusion of renewable generation is lowered for higher penetration levels of the renewable resources. This is due to the high spilling rate of the energy generated from renewable resources. Since, the minimum generation level of the conventional generation plants is fixed, high penetration of the renewable resources causes the total generation greater than the demand during certain hours. Excess generation is subsequently curtailed to minimise the demand and generation mismatch.

\subsection{Variation of Peak and Off-Peak Demand}

The above mentioned scenarios are simulated for the peak and off-peak demand variation in the base case demand data, and also with $5 \%$ and $10 \%$ reduction in the variation between daily peak and off-peak demand. The emission reduction and penetration levels of the renewable resources in the electricity network for different values of peak load shifting index are presented in Fig. 7. It is seen that reducing the variation between the peak and off-peak load, higher emission reduction can be achieved with lower penetration of the renewable resources. It is remarkable that near the penetration level of 50\%, for scenario 1 (S1) and scenario 2 (S2), the change in the peak load shift index is not very effective for overall emission reduction. Similar effect has been found for penetration level near $40 \%$ in the case of scenario 3 (S3). This is because the spilling of the renewable energy starts after the penetration level of $40 \%$. 


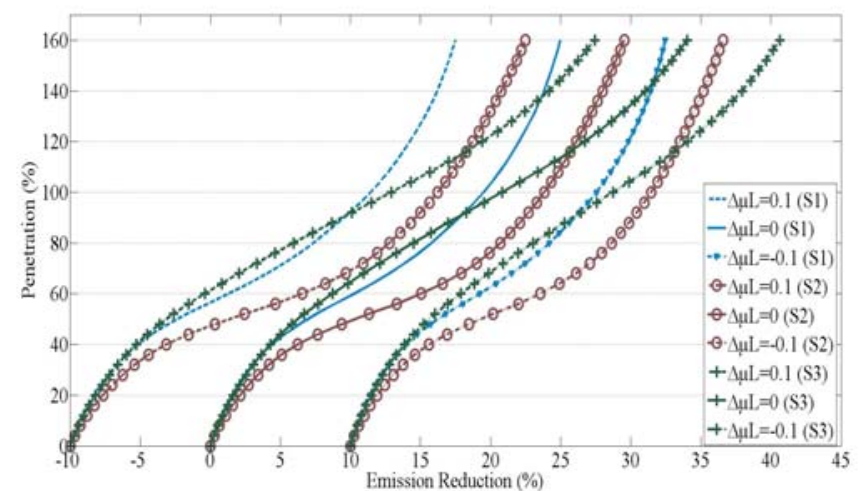

Fig. 6. Emission reduction for varying penetration of renewable generation with different average load demands.

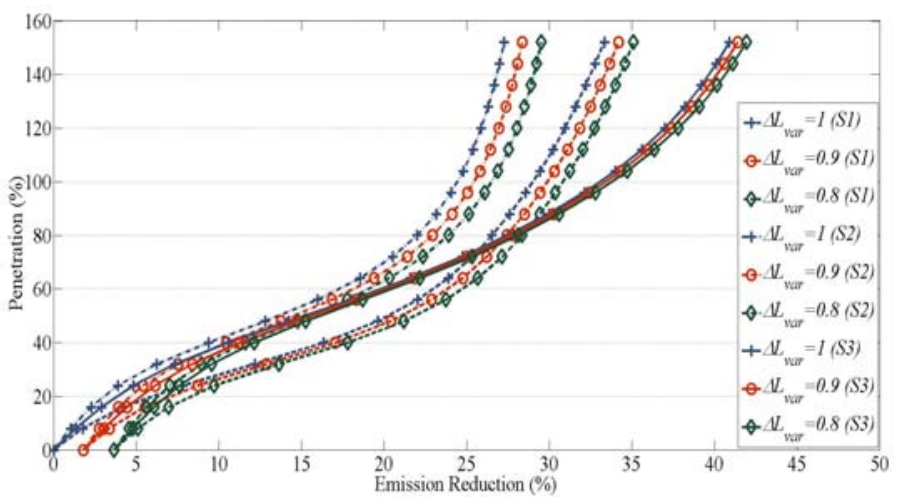

Fig. 7. Emission reduction for varying penetration of renewable generation with different peak and off-peak load demand variations.

\subsection{Changing Generation Flexibility}

By increasing the generation flexibility of the system, it is possible to accommodate more intermittent generation systems such as renewables. The impact of changing the flexibility factor of the system is simulated for the above-listed three scenarios. Unit commitment is used to estimate the energy curtailment from renewable energy generation sources due to the ramp rate limitations and minimum up/down time constraints of the conventional generation plants. For each set of generation flexibility index and penetration level of renewable energy generation sources in each scenario, unit commitment program is run to estimate the absorbable renewable generation in each dispatch interval. Emission reduction performance with the different penetration levels of renewable resources for the generation flexibility of $0.75,0.8$ and 0.85 of the conventional generating systems are shown in Fig. 8. It is found that the flexibility index of the system contributes to the emission reduction at higher penetration level of the renewable energy. This is because for higher penetration levels with high flexibility of the conventional generation systems, the spilling of the renewable energy is less.

\subsection{Changing Generation Mix}

Coal is the predominantly used as a primary fuel source in the conventional generation systems of the NSW. Natural gas is at the second position as the fossil fuel used for electricity generation in NSW. Emission rate of the coal fired plants is higher than that of the gas fired power plants. By reducing the capacity of coal based power plants and increasing the capacity of natural gas based power plants, emission reduction can be achieved. For each value of generation mix index and penetration level of renewable energy generation sources in each scenario, the absorbable renewable generation is estimated for each dispatch interval. The marginal emission of the NSW grid for the fuel mix index of $0.1667,0.2667$ and 0.3667 are estimated using the proposed marginal emission evaluation technique.

The impact of the changing fuel mix of the electricity generation system on the emission reduction and renewable resources penetration level is simulated for the above three scenarios and the results are presented in Fig 9. From the results it is found that for all penetration levels of the renewable resources, the emission reduction performance is found to be similar. 


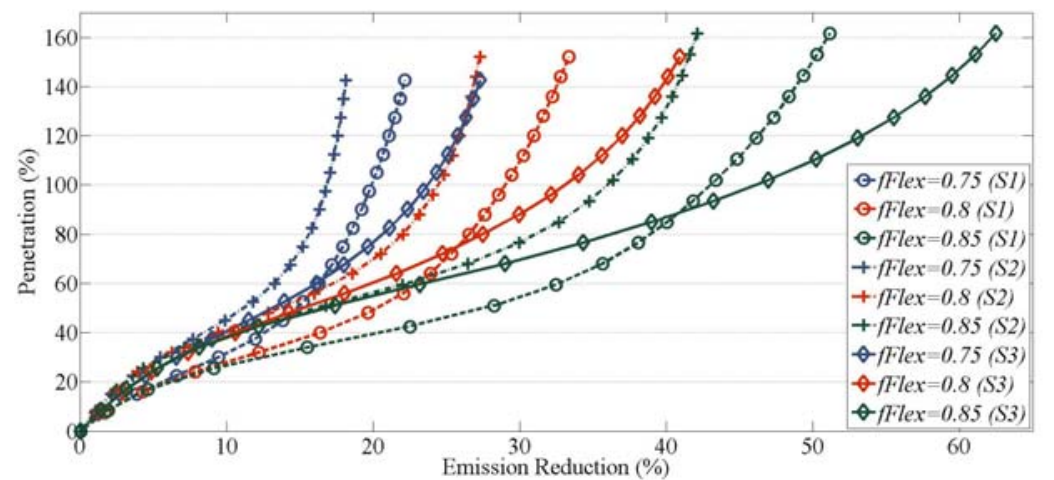

Fig. 8. Emission reduction for varying penetration of renewable generation with different generation flexibility.

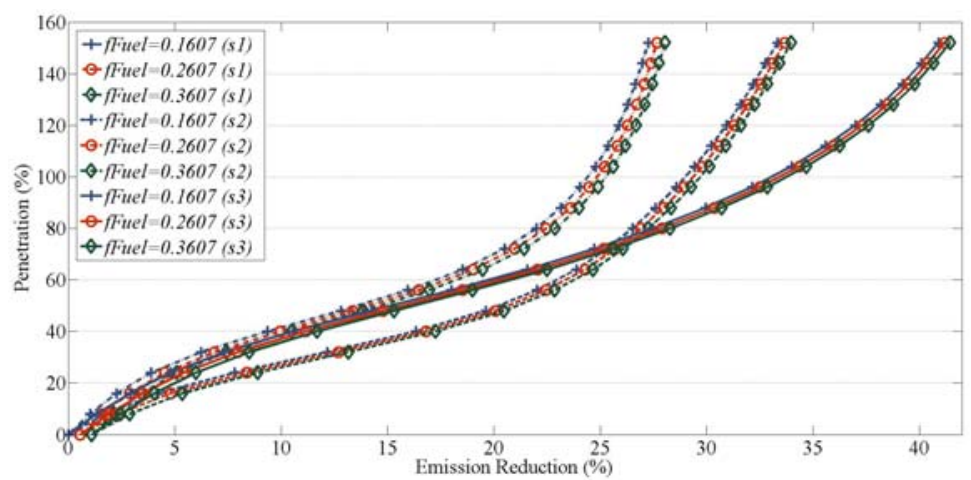

Fig. 9. Emission reduction for varying penetration of renewable generation with different generation mix index.

Thus far, in the above analyses, unit commitment is used to estimate the output of each power plant during each dispatch interval and the emission costs are not taken into account in the formulation. In order to investigate the sensitivity of renewable generation penetration requirement on emission costs to achieve different emission reduction level, a unit commitment program has been implemented with the due consideration of emission costs. In the unit commitment accounting emission costs, the equivalent $\mathrm{CO}_{2}$ emission price is considered as \$23/tonne which is the carbon price for year 2011-2012 in Australia [34]. The marginal emissions are estimated using the proposed method for every iterative step of the unit commitment problem and included in the objective function as the cost of emission.

The impact of the average demand shifting on the renewable generation penetration requirement to achieve different emission reduction level is estimated assuming \$23/tonne carbon price throughout the planning horizon and the results are shown in Fig 10. Comparing the results with and without considering carbon price in unit commitment formulation (Figs. 10 and 6 respectively), it is observed that the trends of variation of renewable generation penetration requirement for emission reduction target level for different scenario are similar. For example, to achieve $20 \%$ emission reduction from electricity generation system of NSW using hybrid combination of solar PV and WECS with equal capacities, 120\%, 95\% and 70\% renewable penetrations are required for the $10 \%, 0 \%$ and $-10 \%$ average demand shifting when carbon price is not considered in the unit commitment, respectively. With the consideration of carbon price in the unit commitment formulation, the renewable penetration drops down to $100 \%, 75 \%$ and $50 \%$ for achieving the same average demand shiftings. Hence, the impacts of demand shifting, generation flexibility and fuel mix on the renewable generation penetration requirement to achieve emission reduction are estimated which can reflect the climate change mitigation strategies in electricity system under 'Carbon Pricing Mechanism'. 


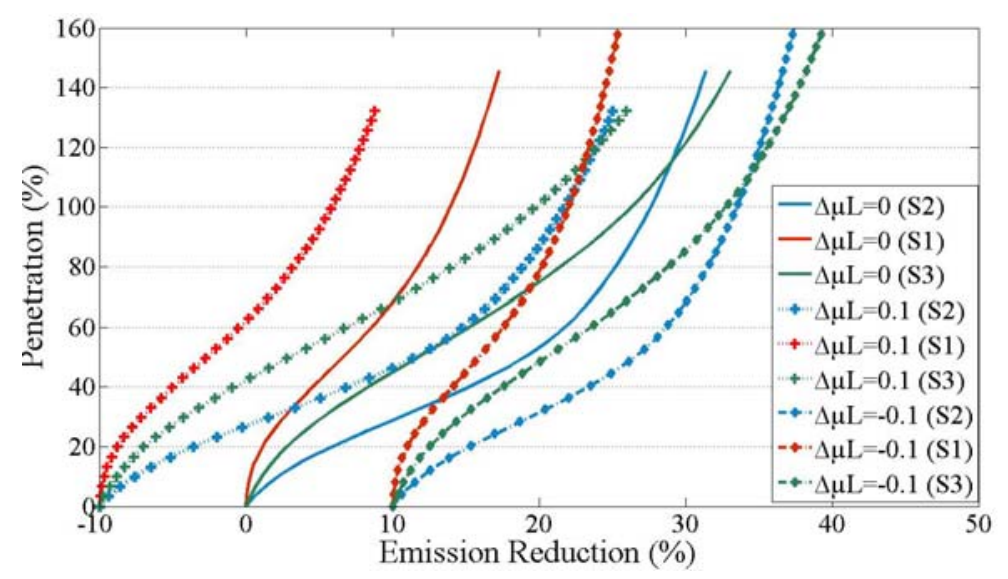

Fig. 10. Emission reduction for varying penetration of renewable generation with different average load demands (estimated accounting carbon price).

Based on the performance analysis with the applicability of all climate change mitigation indices proposed, it is found that only increasing the conventional, i.e. non-renewable generation system flexibility up to 0.85 in scenario 3 (S3) can achieve the $60 \%$ emission reduction target with a renewable generation penetration level of $160 \%$. It is noted that the emission reduction target of $60 \%$ by year 2050 , set by the NSW state government, can be achieved through the combinatorial solution incorporating climate change mitigation strategies along with the integration of renewable power generation. In order to achieve the emission reduction target, impacts of the climate change mitigation technologies on the electricity network should be assessed and deployment of the prospective strategies should be selected accordingly. It is found that the scenario 3 , where hybrid combination of solar PV and WECS are used as the renewable generation systems, has the highest emission reduction capability with high penetration levels of these resources. The assessment of optimal renewable generation mix can be one of the possible future trends to achieve the emission reduction targets.

\section{Conclusion}

The impacts of climate change mitigation strategies on the emission reduction in electricity networks embedded with renewable energy generation resources are assessed in this paper. A mathematical formulation has been developed for examining the effects of different mitigation strategies on the demand and generation in the electricity networks and new mitigation indices are proposed. The overall emission associated with the energy in the grid mix is modelled to account for the time varying load demand in the electricity networks. The proposed model developed based on marginal emissions can be used to assess the performance of the individual generating resources. Penetration levels of advanced renewable generation systems in the state of NSW are assessed for different mitigation indices resulting from the climate change mitigation strategies. The proposed mitigation indices can be used as a measure to select the appropriate climate change mitigation strategies with optimal penetration of renewable generation mix to achieve the emission reduction target. The proposed model has been applied to the electricity network of the state of NSW and results are reported. The results have revealed that with the aid of the proposed climate change mitigation strategies, the overall emission reduction with the integration of different renewable energy generation systems can be maximised. The future research activities are aimed at modelling the impact of individual climate change mitigation technologies on the electricity network and selection of the optimal generation mix for the state of NSW.

\section{Appendix A: Derivation of Total Emissions from Intermediate Demand Power Plants}

Let's assume that the installed capacity of $i^{\text {th }}$ type intermediate demand supplying power plant be $C_{i}$ and dispatched power of the power plant be $g_{i}$ during the system demand level $f_{D}$. Hence the expression for $x_{i}$ and $w_{i}$ can be represented by (A1) and (A2), respectively.

$$
\begin{aligned}
& x_{i}=\frac{C_{i}}{g_{I}-g_{B}} \\
& w_{i}=\frac{g_{i}}{f_{D}-g_{B}}
\end{aligned}
$$

The sum of $w_{i}$ for all the generation plant of same demand type (intermediate demand generation plants) will be equal to one. Now the ratio of operating load to the rated load of the $i^{\text {th }}$ generation plant used to estimate 
marginal emission from the generation plant in equation (12) of the paper can be estimated from equation (A3) as follows.

$$
\frac{g_{i}}{C_{i}}=\frac{w_{i} \times\left(f_{D}-g_{B}\right)}{x_{i} \times\left(g_{I}-g_{B}\right)}
$$

Now for the demand level of $f_{D}$, the marginal emission due to different generation plant dispatched can be estimated from weighted average of the marginal emission from each generation plant. The weighting factor is the ration of dispatched generation power to the total generations from intermediate demand generation plants which is the normalised generated power as shown in equation (A2). Hence the marginal emission from intermediate demand generation plant due to a demand level $f_{D}$ can be estimated using (A4) as shown below.

$$
M E_{G, \text { Int }}\left(f_{D}\right)=\sum_{i} M E_{G, i, \text { Elec }}\left(\frac{w_{i} \times\left(f_{D}-g_{B}\right)}{x_{i} \times\left(g_{I}-g_{B}\right)}\right) \times w_{i}
$$

Hence the total emission from intermediate generation plant due to load level of $f_{D}$ can be estimated using the following equation.

$$
T E_{G, \text { Int }}\left(f_{D}\right)=\left[\sum_{i} M E_{G, i, E l e c}\left(\frac{w_{i} \times\left(f_{D}-g_{B}\right)}{x_{i} \times\left(g_{I}-g_{B}\right)}\right) \times w_{i}\right] \times\left(f_{D}-g_{B}\right)
$$

From equation (A1), it is apparent that fraction of installed generation capacity supplied by the $i^{\text {th }}$ type power plant, $x_{i}$ is independent of generation plant dispatch level and demand level of the grid. However, normalised dispatched power $i^{\text {th }}$ type power plant, $w_{i}$ is the generation plant dependent and estimated from the unit commitment problem for system demand level $f_{D}$.

\section{References}

[1] E.K. Hart, M.Z. Jacobson, A Monte Carlo approach to generator portfolio planning and carbon emissions assessments of systems with large penetrations of variable renewables. Renewable Energy. 36(2011) 22782286.

[2] L.M. Beard, J.B.Cardell, I. Dobson, F. Galvan, D. Hawkins, W. Jewell, M. Kezunovic , T.J. Overbye, P.K. Sen, D.J. Tylavsky. Key Technical Challenges for the Electric Power Industry and Climate Change. IEEE Trans on Energy Convers 2010; 25(2):465-73.

[3] D. Chattopadhyay. Modeling Greenhouse Gas Reduction from the Australian Electricity Sector. IEEE Trans on Power Syst 2010; 25(2):729-40.

[4] T.B. Nguyen,N. Lu, C. Jin. Modeling impacts of climate change mitigation technologies on power grids. Proc of IEEE Power and Energy Soc Gen Meet 2011.

[5] G. Tsilingiridis, C. Sidiropoulos, A. Penaliotis, Reduction of air pollutant emissions using renewable energy sources for power generation in Cyprus. Renewable Energy. 36(2011) 3292-3296.

[6] A. Del Rosso, C. Clark. Methods and tools to estimate carbon emission savings from integration of renewable and T\&D efficiency improvement. Proc of IEEE Power and Energy Soc Gen Meet 2011.

[7] E. Denny, M. O'Malley. Wind generation, power system operation, and emissions reduction. IEEE Trans on Power Syst 2006; 21(1):341-47.

[8] C. De Jonghe, E. Delarue, R. Belmans, W. D’haeseleer. Determining optimal electricity technology mix with high level of wind power penetration. Appl Energy 2011; 88:2231-2238.

[9] Shuai Lu, Y.V. Makarov, Yunhua Zhu, Ning Lu, N.P. Kumar, B.B. Chakrabarti. Unit commitment considering generation flexibility and environmental constraints. Proc of IEEE Power and Energy Soc Gen Meet 2010.

[10] P. Denholm, R.M. Margolis. Evaluating the limits of solar photovoltaics (PV) in traditional electric power systems. Energy Policy 2007; 35(5):2852-61.

[11] P. Denholm, R.M. Margolis. Evaluating the limits of solar photovoltaics (PV) in electric power systems utilizing energy storage and other enabling technologies. Energy Policy 2007; 35(7): 4424-33.

[12] C.L. Weber, P. Jaramillo, J. Marriott, C. Samaras. Uncertainty and variability in accounting for grid electricity in life cycle assessment. Proc of IEEE Intl Symposium on Sustainable Syst and Tech 2009.

[13] Z.A. Muis, H. Hashim, Z.A. Manan, F.M. Taha, P.L. Douglas, Optimal planning of renewable energyintegrared electricity generation schemes with $\mathrm{CO}_{2}$ reduction target.

[14] M. Bianchi, A. De Pascale. Emission calculation methodologies for CHP plants. Energy procedia 2012; 14:1323-1330.

[15] P. Mancarella, G. Chicco. Global and local emission impact assessment of distributed cogeneration systems with partial load models. Appl Energy 2009; 86:2096-2106.

[16] J. Cristobal, G. Guillen-Gosalbez, L. Jimenez, A. Irabien. Optimization of global and local pollutant control in electricity production from coal burning. Appl Energy 2012; 92:369-378. 
[17]F. Vallee, C. Versele, J. Lobry, F. Moiny, Non-sequential Monte Carlo simulation tool to minimize gaseous pollutants emissions in presence of fluctuating wind power. Renewable Energy. 50(2013) 317-324.

[18] T. Gjengedal. Emission constrained unit-commitment (ECUC). IEEE Trans. On Energy Convers 1996; 11(1):132-38.

[19] N.P. Padhy. Unit commitment- A bibliographical survey. IEEE Trans. On Power Syst2004; 19(2): 11961205.

[20] J.H. Talaq, Ferial, M.E. El-Hawary. A summary of environmental/economic dispatch algorithms. IEEE Trans. On Power Syst 1994. 9(3): 1508-16.

[21] E.K. Hart, M.Z. Jacobson. A Monte Carlo approach to generator portfolio planning and carbon emissions assessments of systems with large penetrations of variable renewables. Renewable Energy 2011. 36: 22782286.

[22]F. Vallee, C. Versele, J. Lobry, F. Moiny. Non-sequential Monte Carlo simulation tool in order to minimize gaseous pollutants emissions in presence of fluctuating wind power. Renewable Energy 2013. 50: 317-24.

[23] R. Ramanathan. Emission constrained economic dispatch. IEEE Trans. On Power Syst 1994. 9(4): 19942000.

[24]C. Palanichamy, N.S. Babu, Analytical solution for combined economic and emissions dispatch. Elec Power Syst Research 2008. 78: 1129-1137.

[25] The Office of Environment and Heritage (OEH), The Carbon Pollution Reduction Scheme: Green Paper NSW Government Submission $2011 . \quad$ Online. Available: http://www.environment.nsw.gov.au/publications/cprsgp.htm

[26] Bureau of Resources and Energy Economics, “The Australian energy technology assessment (AETA) 2012: Report”, Online. Available: http://bree.gov.au/publications/aeta.html

[27] M.A. Abdullah, A.P. Agalgaonkar, K.M. Muttaqi. Quantification of emission reduction from electricity network with the integration of renewable resources. Proc of IEEE Power and Energy Soc Gen Meet 2011.

[28] Ning Lu, T. Taylor, Wei Jiang, Chunlian Jin, J. Correia, L.R. Leung, Pak Chung Wong. Climate Change Impacts on Residential and Commercial Loads in the Western U.S. Grid. IEEE Trans on Power Syst 2010; 25(1): 480-88.

[29] Z. Darabi, M. Ferdowsi. Aggregated Impact of Plug-in Hybrid Electric Vehicles on Electricity Demand Profile. IEEE Trans on Sustain Energy 2011; 2(4): 501-8.

[30] National Transmission Network Development Plan 2010, Australian Electricity Market Operator, 2010, access via internet on May 2011, Available: http://wwww.aemo.com.au/planning/2010ntndp_cd/home.htm.

[31] Australian Government. National pollutant inventory: Emission estimation technique manual for fossil fuel electric power generation. Version 2.4: 2005.

[32] Environment Australian. National pollutant inventory: Emission estimation technique manual for Gas supply. 1999.

[33] H. Lund, E. Munster. Management of surplus electricity production from a fluctuating renewable energy source. Appl Energy 2003(November); 76:65-74.

[34] Australian Government Clean Energy Regulator, “Carbon Pricing Mechanism”, Online. Available : http://www.cleanenergyregulator.gov.au/Carbon-Pricing-Mechanism/Pages/default.aspx 